Please cite this paper as follows: Verleye, Katrien (2015) "The co-creation experience from the customer perspective: its measurement and determinants", Journal of Service Management, Vol. 26 Iss: 2, pp.321 - 342.

\title{
The Co-Creation Experience from the Customer Perspective: Its Measurement and
}

\section{Determinants}

Katrien Verleye

\section{Katrien.Verleye@UGent.be}

\author{
Kenan-Flagler Business School at University of North Carolina at Chapel Hill \& Center for \\ Service Intelligence at Ghent University \& Vlerick Business School
}

\section{Author Details}

Katrien Verleye holds a Ph.D in Applied Economics from Ghent University, where she is a member of the Center for Service Intelligence. During her doctoral trajectory, Katrien was visiting doctoral researcher at University of North Carolina at Chapel Hill and research associate at Vlerick Business School. Her research interests include service management, service innovation, value co-creation, and customer engagement behaviors. Her research has been published in Journal of Service Research, Journal of Applied Management and Entrepreneurship, and Journal of Management \& Marketing in Healthcare.

\section{Acknowledgements}

The author thanks Prof. dr. Valarie Zeithaml for her help in developing this research idea and her advice in writing the paper. Furthermore, the author thanks Prof. dr. Bart Larivière for his help with the data analysis. Finally, the author also thanks Prof. dr. Jim Bettman, Prof. dr. Chester Insko, Drs. Arne De Keyser, and the members of her doctoral examination committee for their comments on earlier drafts of this paper. Our sincere gratitude also goes to the two anonymous reviewers and the special issue editors whose comments and suggestions were very helpful to improve this article.

This article is (C) Emerald Group Publishing and permission has been granted for this version to appear here (http://dx.doi.org/10.1108/JOSM-09-2014-0254). Emerald does not grant permission for this article to be further copied/distributed or hosted elsewhere without the express permission from Emerald Group Publishing Limited.' 


\section{The Co-Creation Experience from the Customer Perspective: Its Measurement and Determinants}

Purpose - Companies increasingly opt for co-creation by engaging customers in new product and service development processes. This paper aims to provide insight into the customer experience in co-creation situations and its determinants.

Design/methodology/approach - Our conceptual framework addresses (1) the customer experience in co-creation situations, and (2) its individual and environmental determinants. To examine the degree to which these determinants affect the customer experience in co-creation situations, we start by proposing and testing a multidimensional co-creation experience scale ( $n=66)$. Next, we employ an experiment to test our hypotheses $(n=180)$.

Findings - Higher levels of customer role readiness, technologization, and connectivity positively affect different co-creation experience dimensions. The impact of these dimensions on the overall co-creation experience, however, differs according to customers' expectations in terms of co-creation benefits. Therefore, we conclude that the expected co-creation benefits determine the importance of the level of customer role readiness, technologization, and connectivity for the co-creation experience.

Originality/value - This research generates a better understanding of the co-creation experience by providing insight into the co-creation experience dimensions and their relative importance for customers with different expectations in terms of co-creation benefits. Additionally, this research addresses the implications of customer heterogeneity in terms of expected co-creation benefits for designing co-creation environments, thereby helping managers to generate more rewarding co-creation experiences for their customers. 


\section{The Co-Creation Experience from the Customer Perspective: Its Measurement and}

\section{Determinants}

Academics and practitioners increasingly recognize the importance of engaging customers in the creation of new products and services through co-creation (Payne et al., 2008; Prahalad and Ramaswamy, 2003). In recent years, online tools and communities facilitated co-creation in ideation (e.g., customers generating new ideas in companies' virtual environments), design (e.g., customers designing their own offerings with the help of companies'self-design tools), and development (e.g., user communities testing offerings for defects) (Nambisan, 2002). Therefore, co-creation involves customer engagement in the creation of offerings through ideation, design and development (Bolton and Saxena-Iyer, 2009; Mustak et al., 2013; Vargo and Lusch, 2008).

Despite its acknowledged importance, empirical work about the outcomes of co-creation is rather limited (Carbonell et al., 2009). Extant studies - which have largely been limited to conceptual and qualitative studies - associate co-creation with efficiency gains for firms, such as minimization of new product and service development costs (O'Hern and Rindfleisch, 2008), reduced failure risk (Hoyer et al., 2010), and faster speed to market (Alam, 2002). Additionally, co-creation is related to effectiveness gains for firms, such as a closer fit with customer needs (Fang et al., 2008) and better market reach and acceptance (O'Hern and Rindfleisch, 2008). Empirical studies, however, paid scant attention to the impact of cocreation on the customer experience, although generating better customer experiences is a key rationale for firms to opt for co-creation (Klaus and Maklan, 2012; Payne et al., 2008; Pine and Gilmore, 1999).

This research - which focuses on co-creation from the customer perspective - provides insight into the customer experience in co-creation situations and its determinants. On the one hand, we argue that the co-creation experience depends on customer characteristics, such as 
expected co-creation benefits (i.e., customers' expectations about benefits in co-creation situations) and customer role readiness (i.e., the degree to which customers are ready to fulfill their role as co-creators). On the other hand, we argue that co-creation experiences depend on characteristics of co-creation environments, such as technologization (i.e., the availability of online tools and devices that aid in achieving a co-creation task) and connectivity (i.e., the availability of help from other customers). To examine the impact of characteristics of both customers and co-creation environments on the customer experience in co-creation situations, this research employs an experiment. As background to this experiment, we propose a multidimensional co-creation experience scale, thereby building on the customer experience literature (Klaus and Maklan, 2012; Palmer, 2010; Verhoef et al., 2009).

The subsequent section presents our theoretical framework on the customer experience in co-creation situations. Next, we describe the experiment that tests our hypotheses. We close by discussing the results, future research opportunities, and managerial implications.

\section{Theoretical Framework and Hypotheses}

This section addresses the customer experience in co-creation situations and its determinants. In line with the customer experience literature (Gentile et al., 2007; Holbrook and Hirschman, 1982; Verhoef et al., 2009), we discuss individual determinants (characteristics of co-creating customers) and environmental determinants (characteristics of co-creation environments). Figure 1 visualizes our theoretical framework.

Insert Figure 1 about here

\section{The Co-Creation Experience}

Expected co-creation benefits. Social exchange theory holds that people who put more effort into an activity - such as co-creating customers - are motivated by the expected returns (Blau, 2004). The literature on customer motives to co-create value confirms that customers 
expect different benefits in return for co-creation. Drawing from the uses and gratification framework, Namibian and Baron (2009) argue that customers who co-create in virtual environments expect (1) hedonic benefits (i.e., pleasurable experiences); (2) cognitive benefits (i.e., knowledge about products, services, and technologies); (3) social benefits (i.e., relational ties among participants); and (4) personal benefits (i.e., status and self-efficacy). Based on a review of the virtual co-creation literature, Füller (2010) confirms that customers expect (1) intrinsic playful tasks ( $c f$. hedonic benefits), (2) opportunities to keep up with new ideas and develop skills ( $c f$. cognitive benefits), (3) opportunities to connect with like-minded people (cf. social benefits), and/or (4) self-efficacy and recognition ( $c f$. personal benefits). This review, however, adds the importance of (5) pragmatic benefits in the form of solutions better meeting personal needs; and (6) economic benefits in the form of monetary rewards.

Remarkable is that the aforementioned expected co-creation benefits were identified in not only research on virtual co-creation but also research on co-creation in general (Etgar, 2008; Hoyer et al., 2010). This research grouped the expected co-creation benefits into broader categories. Etgar (2008), for instance, identified three broad categories of expected cocreation benefits. The first category refers to economic benefits, including reduction of risks associated with receiving inappropriate products or services ( $c f$. pragmatic benefits) and a compensation in line with the effort made ( $c f$. economic benefits). The second category refers to social benefits, including both opportunities for social contact ( $c f$. social benefits) and better status and social esteem ( $c f$. personal benefits). The third category refers to psychological benefits, which include enjoyment, fun, and excitement ( $c f$. hedonic benefits) and learning and mastering new skills and techniques ( $c f$. cognitive benefits). Hoyer et al. (2010) make a similar categorization, except for the fact that cognitive benefits are considered as a separate category of expected co-creation benefits. Therefore, we conclude that the expected co-creation benefits are: 
- hedonic benefits: having pleasurable experiences

- cognitive benefits: acquiring new knowledge/skills

- social benefits: being able to connect with other people

- personal benefits: gaining a better status and recognition

- pragmatic benefits: solutions better meeting personal needs

- economic benefits: compensation in line with effort made.

Co-creation experience dimensions. Building on the gaps model that underlines the importance of balancing customer perceptions with expectations to deliver service quality (Zeithaml et al., 1990), we argue that the co-creation experience depends on the degree to which expected co-creation benefits are met. In other words, the expected co-creation benefits that customers actually get in return for co-creation determine their overall co-creation experience. Therefore, we argue that the overall co-creation experience is driven by six cocreation experience dimensions ${ }^{[1]}$ :

- hedonic experience: actually getting hedonic benefits in return for co-creation

- cognitive experience: actually getting cognitive benefits in return for co-creation

- social experience: actually getting social benefits in return for co-creation

- personal experience: actually getting personal benefits in return for co-creation

- pragmatic experience: actually getting pragmatic benefits in return for co-creation

- economic experience: actually getting economic benefits in return for co-creation.

Hypothesis 1: the (a) hedonic, (b) cognitive, (c) social, (d) personal, (e) pragmatic, and (f) economic experience will have a positive impact on the overall co-creation experience. 


\section{Characteristics of Co-Creating Customers}

Based on self-determination theory (Ryan and Deci, 2000), one could argue that customer engagement in co-creation is a unique function of intrinsic benefits (doing activities for the sake of the activities themselves), extrinsic benefits (doing activities because of external forces), and internalized extrinsic benefits (doing activities in consequence of external forces that are made one's own). Füller (2010) confirms that combinations of intrinsic benefits (hedonic benefits), extrinsic benefits (pragmatic and economic benefits), and internalized extrinsic benefits (cognitive, social and personal benefits) drive customer engagement in cocreation, but these combinations differ among customers. Since customers expect different cocreation benefits, we argue that not all co-creation experience dimensions - which reflect benefits customers actually get in return for co-creation - are equally important for all customers. Responding to Palmer (2010)'s call to take the moderating influence of customer heterogeneity into account when measuring customer experiences, we hypothesize that:

Hypothesis 2: expected co-creation benefits moderate the impact of the (a) hedonic, (b) cognitive, (c) social, (d) personal, (e) pragmatic, and (f) economic experience on the overall co-creation experience.

Expected co-creation benefits are not the only individual characteristics that affect customer experiences. Drawing from role theory (Kahn et al., 1964), the customer participation literature suggests that customer experiences also depend on the degree to which customers are ready to fulfill their role or customer role readiness. Customer role readiness reflects (1) the degree to which customers are motivated to fulfill their role or their motivation, (2) the degree to which customer know how they are expected to perform their role or their role clarity, and (3) the degree to which customers are able to perform their expected role or their ability (e.g., Auh et al., 2007; Meuter et al., 2005). Specifically, this line 
of research has shown that customer motivation, role clarity, and ability - which comprise customer role readiness - help customers to constructively participate in service creation and delivery processes. Therefore, we hypothesize that customer role readiness also affects the cocreation experience dimensions.

Hypothesis 3: customer role readiness will have a positive impact on the (a) hedonic, (b) cognitive, (c) social, (d) personal, (e) pragmatic, and (f) economic experience.

\section{Characteristics of Co-Creation Environments}

Since theorizing about properties of co-creation environments is lacking, we reviewed the cocreation literature (e.g., Alam, 2002; Thomke and von Hippel, 2002; Franke et al., 2008; Nambisan and Baron, 2009; Füller, 2010). This review revealed that co-creation environments exhibit different levels of what is labeled as technologization and connectivity.

Technologization. We define technologization as the availability of online tools and devices that aid in achieving a co-creation task. In recent years, the co-creation literature has paid major attention to co-creation environments with high levels of technologization, such as self-design tools and user innovation toolkits. In these environments, firms allow individual customers to design their own products and services (Franke and Schreier, 2010; Thomke and von Hippel, 2002). Additionally, firms can encourage customers to share new product and service ideas with other customers in virtual customer environments or VCEs (Füller, 2006; Füller, 2010; Nambisan and Baron, 2009, 2010). Co-creation, however, can also occur in environments with low levels of technologization, such as during user meetings, face-to-face interviews, and brainstorming or focus groups (Alam, 2002; Schirr, 2012). The main question is whether the level of technologization affects the co-creation experience dimensions. 
We argue that higher levels of technologization - rather than the co-creation process itself - positively affect all co-creation experience dimensions. Firstly, Franke et al. (2008) argue that user toolkits for innovation - and thus high technologization - facilitate trial-and-error experimentation for customers. Secondly, high technologization also helps customers to visualize the outcome (Franke et al., 2008). Thirdly, trial-and-error experimentation and visualization of the outcome enable customers to learn their preferences iteratively until the optimal product or service is created (Franke and Piller, 2004). Finally, high technologization also accelerates the co-creation process (Thomke and von Hippel, 2002).

Hypothesis 4: higher levels of technologization in the co-creation environment will have a positive impact on the (a) hedonic, (b) cognitive, (c) social, (d) personal, (e) pragmatic, and (f) economic experience.

Connectivity. We define connectivity as the availability of help from other customers. Cocreation environments represent different levels of connectivity. On the one hand, there are co-creation environments where customers get little help from other customers (low connectivity), such as user meetings and face-to-face interviews (Alam, 2002), self-design tools and toolkits for user innovation that do not allow for help from other customers (Franke and Schreier, 2010), or toolkits for user innovation that only allow for feedback on designs from other customers (Franke et al., 2008). On the other hand, there are co-creation environments where customers have several opportunities to support each other throughout the co-creation process (high connectivity), such as brainstorming groups (Alam, 2002; Schirr, 2012), online communities (von Hippel, 2001) and VCEs (Nambisan and Baron, 2009, 2010).

Few studies compare co-creation environments with low versus high connectivity. Nevertheless, higher connectivity levels are viewed as a promising way to generate better customer experiences (Füller, 2010). Jeppesen (2005), for instance, argues that higher levels 
of connectivity may help customers to become more successful co-creators. Franke and Shah (2003) confirm that "the system of mutual help in the communities works well" (p. 166). Since these authors show that higher connectivity levels positively affect customers' satisfaction with the newly-generated products and services, we hypothesize that:

Hypothesis 5: higher levels of connectivity in the co-creation environment will have a positive impact on the (a) hedonic, (b) cognitive, (c) social, (d) personal, (e) pragmatic, and (f) economic experience.

Control variables. Apart from the level of connectivity, characteristics of interactions between co-creation partners can also affect co-creation experience dimensions. Previous research has shown that interactional quality affects the social and hedonic experience (Downie et al., 2008). We argue that the same is true for other experience dimensions, since several authors suggest that customers' relationship with their co-creation partners influences their experience (e.g., Payne et al., 2008). Therefore, we control for the impact of interactional quality - and specifically acquaintanceship between co-creation partners and the co-creation partner's appreciation for the customer's input - on the co-creation experience dimensions.

\section{Method}

\section{Participants and Design}

One hundred and eighty undergraduate students at a Southern United States university were recruited to participate in an experiment for course credit (62\% males, $38 \%$ females). Subjects were invited in pairs at different times and pairs were randomly assigned to conditions in a two (technologization: low versus high) by two (connectivity: low versus high) mixed design. 


\section{Procedure}

The pairs of subjects were told that the study focused on interior design preferences of undergraduate students. The pairs of subjects were asked to design their ideal bedroom interior after graduation. In the low connectivity groups, pairs were split and the two subjects were asked to sit at different desks. In the high connectivity groups, pairs were asked to sit around one desk. In the low technologization groups, paper, pencil, and ruler were provided, while a computer with interior design software was provided to the high technologization groups (see Appendix). Subjects received instruction forms, which mentioned that they had 20 minutes to design their ideal bedroom (forms available upon request). The instruction form of the low connectivity groups asked subjects to do the task individually and then meet with the other subject to briefly comment on each other's design. In the high connectivity group, subjects were asked to complete the task together. After completing the design task, subjects in all conditions were asked to fill out a questionnaire about how they experienced the task. The questionnaire included the following scales: overall co-creation experience, co-creation experience dimensions, customer role readiness, the expected co-creation benefits, and control variables.

\section{Development and Pretest of Co-Creation Experience Scale}

In line with calls for developing multidimensional customer experience scales (e.g., Verhoef et al., 2009), we developed a scale measuring the co-creation experience as a multidimensional phenomenon (1 (strongly disagree) to 7 (strongly agree) scale). This scale reflects the degree to which customers actually get hedonic, cognitive, social, personal, pragmatic, and economic benefits in return for co-creation (see Table 1). Additionally, our cocreation experience scale also includes four items using seven-point semantic differential scales to capture the overall co-creation experience, anchored by dissatisfactory-satisfactory, negative-positive, poor-excellent, and disappointing-delightful. 
Insert Table 1 about here

To validate the seven-dimensional structure of our co-creation experience scale ${ }^{[2]}$, we conducted a pretest among $\mathrm{PhD}$ students $(n=66)$. $\mathrm{PhD}$ students represent co-creating customers because they generate ideas and further elaborate on these ideas in collaboration with university faculty. A principal axis factoring (oblique rotation) on the 26 co-creation experience items extracted six instead of seven factors with eigenvalues greater than one. Further analysis revealed that personal and social experience items loaded on one factor, which is in line with the aforementioned broader categorization of co-creation benefits ( $c f$. Etgar, 2008). Factor loadings were satisfactory $(\geq .50)$, except for "The risk of failure was limited" and "I gained a sense of accomplishment". These items were deleted and the same is true for "It raised ideas that I can introduce to others", because this item loaded on the wrong factor. Without these items, the factors showed strong reliability (Cronbach's alpha $\geq .80$ ). Based on these results, the validation of our co-creation experience scale in the main study will start from a six-dimensional structure for the confirmatory factor analysis (CFA).

\section{Scales and Validation}

Customer experience. After completing the co-creation task in the experiment, subjects were asked to rate how they experienced participation in the task. The CFA of the sixdimensional structure demonstrated an acceptable fit. The data also showed convergent validity, because all item loadings were significant and all construct reliabilities (CR) were greater than .70 and all average variance extracted (AVE) exceeded .50. The factor correlations were significantly different from unity - based on the confidence interval around the estimated factor correlation - and the AVEs for each construct exceeded the squared correlation between factors (Fornell and Larcker, 1981). The only exception was the pragmatic and economic experience: there was no evidence for discriminant validity. 
Therefore, a five-dimensional structure with the items of the pragmatic and economic experience dimension loading on one factor - as also suggested by the broader categorization of co-creation benefits ( $c f$. Etgar, 2008) - was assessed using CFA. Table 2 shows individual items and item loadings. The results demonstrate an acceptable fit, convergent validity, and discriminant validity for all co-creation experience dimensions (see Table 2 and 3). Therefore, we used mean scores for the hedonic, cognitive, social/personal, pragmatic/economic, and overall co-creation experience in further analyses.

Insert Table 2 and 3 about here

Expected co-creation benefits. Subjects were asked which factors were comparably the most important with respect to future engagement in new product and service development: (1) having fun (expected hedonic benefit), (2) acquiring new knowledge/skills (expected cognitive benefit), (3) being able to connect with other people (expected social benefits), (4) gaining a better status and recognition (expected personal benefits), (5) getting products and services better meeting their needs (expected pragmatic benefits), and (6) a compensation in line with the effort made (expected economic benefits). Subjects were asked to rank the factors allocating rank " 1 " for most important, rank " 2 " for the second most important and so forth. This scale is not a pure rank-order scale, as subjects could give factors the same rank if these factors were equally important for them. The scores were reversed for further analysis. In line with the study of Füller (2010), we conducted a cluster analysis on the scores for the importance of the expected co-creation benefits. Considering the literature on procedures to increase the reliability of cluster analysis solutions (e.g., Ketchen and Shook, 1996), we opted for a two-stage procedure. First, we determined an 'optimum' cluster number and starting means by a hierarchical cluster analysis using Ward's method. Next, this cluster solution was used as input for a $K$-means cluster analysis (see Figure 2 for cluster means). Figure 2 shows 
that we identified two groups of subjects in terms of expected co-creation benefits, by which the first group mainly expects hedonic benefits and the second group mainly expects social/personal and pragmatic/economic benefits In line with Füller (2010)'s findings, we labeled these groups as respectively 'intrinsically interested customers' and 'extrinsically interested customers'.

Insert Figure 2 about here

Customer role readiness. Customer role readiness refers to customer motivation, role clarity, and ability. To capture customer motivation for the co-creation task, subjects were asked to indicate whether the task was relevant to them using seven-point semantic differential scales anchored by irrelevant/relevant, unimportant/important, and does not mean a lot to me/means a lot to me (Cronbach's alpha $=.95)$. Subjects were also asked to rate the clarity of their role and their ability to fulfill their role on a 1 (strongly disagree) to 7 (strongly agree) scale. Role clarity was measured by four items of the role ambiguity scale (Rizzo et al., 1970): "I felt certain about my role", "I knew exactly what was expected of me", "Explanation of what had to be done was clear", and "I knew what my responsibilities were" (Cronbach's alpha $=.88)$. Ability was measured by a four-item scale (Beehr et al., 1976): "It seemed like I had too few skills and competences to fulfill my task" (reversed item), "I was given enough time to do what was expected of me", "I had the knowledge and skills to do what was expected of me", and "It seemed like I had too much work for one person to do" (reversed item) $($ Cronbach's alpha $=.75)$. Because the internal consistency was satisfactory, we used mean scores of customer motivation, role clarity, and ability in further analyses.

Control variables. To control for interactional quality, subjects were asked to rate the acquaintanceship with their co-creation partner and the degree to which they perceived that their co-creation partner appreciated their input during co-creation (1 (strongly disagree) to 7 
(strongly agree) scale). Acquaintanceship with their co-creation partner was measured by two items: "Prior to this experiment, I knew the person with whom I collaborated during the task" and - in case they knew each other - "Prior to this experiment, I got along well with the person with whom I collaborated". Since people who knew each other prior to the experiment indicated that they also got along well with each other, we only used scores on the first item in further analysis. The degree to which the co-creation partner appreciated other customers' input during co-creation was measured by one item: "The person with whom I collaborated during the task liked my ideas”.

\section{Results}

In our data set, observations of subjects were nested within pairs. To control for correlations between observations within pairs and thus to control for dependence in the data, we opted for a two-level model to test our hypotheses. To gain insight into the antecedents (independent variables) of different co-creation experience dimensions and consequently the impact of these co-creation experience dimensions (mediating variables) on the overall co-creation experience (dependent variable), we ran a two-level mediation model (Yuan and MacKinnon, 2009). Specifically, we ran a Bayesian two-level mediation model using Markov Chain Monte Carlo (MCMC) techniques, since Bayesian inference is particularly advantageous in analyzing multilevel mediation (Gelman and Hill, 2007) and valid in small samples (Hox, 2010). In line with Gelman and Rubin (1992), we ran three independent MCMC chains with different starting points and 10,000 iterations each, by which the first half is considered as the "burn-in" phase and the remaining half is used to estimate the posterior distribution for the parameters. This results in a distribution based on 15,000 data points $(5,000$ iterations for each

of the three chains). To assess the convergence of the MCMC algorithm, we inspected the Gelman-Rubin convergence statistic R, autocorrelation plots, and trace plots of the residual variance for each parameter estimate ${ }^{[3]}$. 
Let $i$ be the pair of subjects under investigation (i.e., second-level units), and $j$ the subjects within these pairs (i.e., first-level units). A two-level mediation model can be expressed as follows:

At the first level,

$\mathrm{HE}_{\mathrm{ij}}=\beta_{5 \mathrm{j}}+\alpha_{1} \mathrm{MOT}_{\mathrm{ij}}+\alpha_{2} \mathrm{RC}_{\mathrm{ij}}+\alpha_{3} \mathrm{AB}_{\mathrm{ij}}+\alpha_{4} \mathrm{TECH}_{\mathrm{ij}}+\alpha_{5} \mathrm{CONN}_{\mathrm{ij}}+\alpha_{6} \mathrm{TECO}_{\mathrm{ij}}+\alpha_{7} \mathrm{ACQ}_{\mathrm{ij}}+\alpha_{8} \mathrm{APP}_{\mathrm{ij}}+e_{5 \mathrm{ij}}$,

$\mathrm{CE}_{\mathrm{ij}}=\beta_{6 \mathrm{j}}+\alpha_{9} \mathrm{MOT}_{\mathrm{ij}}+\alpha_{10} \mathrm{RC}_{\mathrm{ij}}+\alpha_{11} \mathrm{AB}_{\mathrm{ij}}+\alpha_{12} \mathrm{TECH}_{\mathrm{ij}}+\alpha_{13} \mathrm{CONN}_{\mathrm{ij}}+\alpha_{14} \mathrm{TECO}_{\mathrm{ij}}+\alpha_{15} \mathrm{ACQ}_{\mathrm{ij}}+\alpha_{16} \mathrm{APP}_{\mathrm{ij}}+e_{6 \mathrm{ij}}$,

$\mathrm{SPE}_{\mathrm{ij}}=\beta_{7 \mathrm{j}}+\alpha_{17} \mathrm{MOT}_{\mathrm{ij}}+\alpha_{18} \mathrm{RC}_{\mathrm{ij}}+\alpha_{19} \mathrm{AB}_{\mathrm{ij}}+\alpha_{20} \mathrm{TECH}_{\mathrm{ij}}+\alpha_{21} \mathrm{CONN}_{\mathrm{ij}}+\alpha_{22} \mathrm{TECO}_{\mathrm{ij}}+\alpha_{23} \mathrm{ACQ}_{\mathrm{ij}}+\alpha_{24} \mathrm{APP}_{\mathrm{ij}}+e_{7 \mathrm{ij}}$

$\mathrm{PEE}_{\mathrm{ij}}=\beta_{8 \mathrm{j}}+\alpha_{25} \mathrm{MOT}_{\mathrm{ij}}+\alpha_{26} \mathrm{RC}_{\mathrm{ij}}+\alpha_{27} \mathrm{AB}_{\mathrm{ij}}+\alpha_{28} \mathrm{TECH}_{\mathrm{ij}}+\alpha_{29} \mathrm{CONN}_{\mathrm{ij}}+\alpha_{30} \mathrm{TECO}_{\mathrm{ij}}+\alpha_{31} \mathrm{ACQ}_{\mathrm{ij}}+\alpha_{32} \mathrm{APP}_{\mathrm{ij}}+e_{8 \mathrm{ij}}$,

$\mathrm{OCE}_{\mathrm{ij}}=\beta_{9 \mathrm{j}}+\beta_{1} \mathrm{HE}_{\mathrm{ij}}+\beta_{2} \mathrm{CE}_{\mathrm{ij}}+\beta_{3} \mathrm{SPE}_{\mathrm{ij}}+\beta_{4} \mathrm{PEE}_{\mathrm{ij}}+e_{9 \mathrm{ij}}$,

where "HE" denotes hedonic experience, "MOT" customer motivation, "RC" customer role clarity, "AB" customer ability, "TECH" technologization, "CONN" connectivity, "TECO" interaction between technologization and connectivity, "ACQ" acquaintanceship with cocreation partner, "APP" co-creation partner's appreciation for the customer's input, "CE" cognitive experience, "SPE" social/personal experience, "PEE" pragmatic/economic experience, and "OCE" overall co-creation experience.

At the second level,

$$
\begin{aligned}
& \beta_{5 \mathrm{j}}=\beta_{5}+u_{5 \mathrm{j}}, \\
& \beta_{6 \mathrm{j}}=\beta_{6}+u_{6 \mathrm{j}}, \\
& \beta_{7 \mathrm{j}}=\beta_{7}+u_{7 \mathrm{j}}, \\
& \beta_{8 \mathrm{j}}=\beta_{8}+u_{8 \mathrm{j}}, \\
& \beta_{9 \mathrm{j}}=\beta_{9}+u_{9 \mathrm{j}} .
\end{aligned}
$$


At the first level, $e_{5 \mathrm{ij}}, e_{6 \mathrm{ij}}, e_{7 \mathrm{ij}}, e_{8 \mathrm{ij}}$ and $e_{9 \mathrm{ij}}$ represent residuals of respectively the mediating variables (co-creation experience dimensions) and the dependent variable (overall co-creation experience). The parameters $\beta_{5 \mathrm{j}}, \beta_{6 \mathrm{j}}, \beta_{7 \mathrm{j}}, \beta_{8 \mathrm{j}}$, and $\beta_{9 \mathrm{j}}$ are random intercepts, which allow different pairs to have different regression intercepts for the mediating and dependent variables. The relationships between the mediating variables and the dependent variable after adjusting for the effects of the independent variables - are represented in the remaining $\beta s$, whereas the $\alpha$ s represent parameter estimates for the relationships between the independent variables and the mediating variables. At the second level, $\beta_{5}, \beta_{6}, \beta_{7}$, and $\beta_{8}$ represent average intercepts of the mediating and dependent variables and $u_{5 \mathrm{j}}, u_{6 \mathrm{j}}, u_{7 \mathrm{j}}$, and $u_{8 \mathrm{j}}$, the second-level residuals.

Insert Table 4 about here

Table 4 presents the findings of the Bayesian two-level mediation model. The first column lists the antecedents of the co-creation experience dimensions (MOT, RC, AB, TECH, CONN, TECO, ACQ, and APP) and the antecedents of the overall co-creation experience (HE, CE, SPE, PEE). The second to sixth columns detail their estimated impact and significance level on respectively the co-creation experience dimensions (HE, CE, SPE, PEE) and the overall co-creation experience (OCE). In this section, we discuss (1) the impact of the co-creation experience dimensions on the overall co-creation experience, and (2) the antecedents of different co-creation experience dimensions.

\section{Impact of Co-Creation Experience Dimensions on Overall Co-Creation Experience}

Table 4 shows that the hedonic, cognitive, and social/personal experience positively affect the overall co-creation experience, whereas the pragmatic/economic experience did not have an impact. Therefore, we support H1a-d and reject H1e-f. 
To test H2a-f, we had to evaluate whether the impact of the co-creation experience dimensions on the overall co-creation experience depends on the expected co-creation benefits. As mentioned before, a cluster analysis on the expected co-creation benefits identified intrinsically and extrinsically interested customers. Therefore, we compared the impact of the co-creation experience dimensions on the overall co-creation experience for intrinsically and extrinsically interested customers.

The results of a two-level Bayesian model on the impact of the co-creation experience dimensions on the overall co-creation experience for intrinsically interested customers revealed that their overall co-creation experience is improved by better hedonic and cognitive experiences (see Table 5). The results of a two-level Bayesian model on the impact of the cocreation experience dimensions on the overall co-creation experience for the extrinsically interested customers revealed that their overall co-creation experience was improved by better hedonic and social/personal experiences (see Table 5).

Insert Table 5 about here

In sum, the results of the analyses show that the impact of some co-creation experience dimensions on the overall co-creation experience depends on the expected co-creation benefits. Specifically, the impact of cognitive and social/personal experiences on the overall co-creation experience differs for intrinsically and extrinsically interested customers. As a result, $\mathrm{H} 2 \mathrm{~b}-\mathrm{d}$ are supported. $\mathrm{H} 2 \mathrm{a}$ and $\mathrm{H} 2 \mathrm{e}-\mathrm{f}$ are rejected, since the impact of the hedonic experience and the pragmatic/economic experience does not differ across intrinsically and extrinsically interested customers.

\section{Antecedents of Different Co-Creation Experience Dimensions}

Impact of customer role readiness on co-creation experience dimensions. Table 4 shows that customer motivation positively affected all co-creation experience dimensions, except for 
the social/personal experience. Role clarity had a significant positive impact on all co-creation experience dimensions, except for the hedonic experience. Finally, the results revealed that ability had a positive impact on the hedonic experience dimension. Therefore, H3a-f are mainly supported.

Impact of co-creation environment on co-creation experience dimensions. Table 4 shows that subjects in co-creation situations with high technologization evaluated the hedonic experience more favorably than subjects in co-creation situations with low technologization, but this effect is not significant $(p=.05)$. H4a is thus not supported. Next, we also reject $\mathrm{H} 4 \mathrm{~b}$, since subjects in co-creation situations with high technologization did not evaluate the cognitive experience more favorably than subjects in co-creation situations with low technologization. When it comes to the social/personal experience, there was no significant main effect for technologization. Therefore, H4c-d were also rejected. Finally, Table 4 shows that subjects in co-creation situations with high technologization evaluated the pragmatic/economic experience more favorably than subjects in co-creation situations with low technologization, but this effect was not significant $(p=.07)$. H4e-f are thus not supported.

Regarding the impact of connectivity on different co-creation experience dimensions, Table 4 shows that the hedonic experience was not significantly different in co-creation situations with high versus low connectivity $(p=.08)$. Moreover, the same goes for the cognitive experience. Therefore, $\mathrm{H} 5 \mathrm{a}$ and $\mathrm{H} 5 \mathrm{~b}$ were rejected. Subjects in co-creation situations with high connectivity evaluated the social/personal experience more favorably than subjects in co-creation situations with low connectivity, but this effect was not significant $(p=.08)$. H5c-d was thus also rejected. Finally, we also rejected H5e-f, since the level of connectivity did not significantly influence the pragmatic/economic experience.

The aforementioned results suggest that technologization and connectivity did not affect the co-creation experience dimensions. The effects of technologization and connectivity on 
the cognitive experience, however, were qualified by a significant interaction effect between technologization and connectivity. Figure 3 depicts the cell means for the interaction between technologization and connectivity, thereby revealing that subjects in co-creation situations with low connectivity did not evaluate the cognitive experience more favorably when there was high versus low technologization. In contrast, subjects in co-creation situations with high connectivity had a better cognitive experience when there was high versus low technologization.

Insert Figure 3 about here

Impact of control variables on all co-creation experience dimensions. Table 4 shows that acquaintanceship with the co-creation partner had no impact on the co-creation experience dimensions, while the co-creation partner's appreciation for the customer's input had a significant positive impact on all co-creation experience dimensions. In other words, not only the level of connectivity but also some characteristics of the interactions with co-creation partners affect the customer experience in co-creation situations.

\section{Discussion}

\section{The Co-Creation Experience}

This research contributes to the co-creation and new product and service development literature by providing insight into the customer experience in co-creation situations. First, empirical work about co-creation outcomes - not in the least for customers - is rather scarce (Carbonell et al., 2009). To improve our understanding of the customer experience in cocreation situations, this research explored the co-creation experience dimensions and identified hedonic, cognitive, social, personal, pragmatic, and economic experience dimensions. By proposing and testing a multidimensional co-creation experience scale, this 
research also extends the customer experience literature (e.g., Klaus and Maklan, 2012; Verhoef et al., 2009).

Next, this research investigated how the co-creation experience is affected by individual determinants (i.e., characteristics of co-creating customers) and environmental determinants (i.e., characteristics of co-creation environments). By doing so, this research builds on extant research that merely compared customer outcomes - such as satisfaction and willingness-topay - for co-created products and services with the outcomes that standard products and services generate for customers (e.g., Franke and Piller, 2004; Franke and von Hippel, 2003). Specifically, this research showed that not only the co-creation process itself but also characteristics of co-creation environments and co-creating customers affect customer outcomes (here, the overall co-creation experience).

Regarding characteristics of co-creation environments, the experimental study showed that a combination of technologization and connectivity can improve the overall co-creation experience by generating better cognitive experiences. In other words, co-creation environments with high technologization and connectivity - such as online customer communities or VCEs - can generate better overall co-creation experiences than other cocreation environments by generating significantly more learning opportunities. This finding improves our understanding of online customer communities and VCEs (Füller, 2010).

Regarding characteristics of co-creation customers, the experimental study showed that customer role readiness and appreciation from co-creation partners have a positive impact on most co-creation experience dimensions and the overall co-creation experience. The overall co-creation experience, however, is also affected by customer expectations in terms of cocreation benefits. More particularly, the expected co-creation benefits moderate the impact of the co-creation experience dimensions on the overall co-creation experience. This finding 
contributes to the customer experience literature, which suggested to take individual differences into account when measuring customer experiences (Palmer, 2010).

By demonstrating that the impact of co-creation experience dimensions - in particular the cognitive and social/personal experience - on the overall co-creation experience depends on the expected co-creation benefits, this research suggests that co-creation preferences differ according to customer's expectations in terms of co-creation benefits. Co-creation environments with high technologization and connectivity, for instance, improve the cognitive experience, but this co-creation experience dimension only affects the overall co-creation experience of intrinsically interested customers. This finding demonstrates that customer heterogeneity in terms of expected co-creation benefits needs to be considered when designing co-creation environments, as suggested by Berry et al. (2010).

\section{Managerial Implications}

Although the importance of technologization and connectivity, customer role readiness, and appreciation from co-creation partners can differ according to customers' expectations in terms of co-creation benefits, all aforementioned factors contribute to the co-creation experience.

Since the co-creation partner's appreciation for the customer's input has a positive impact on the co-creation experience, it is important to ensure that co-creating customers do not experience failure. This suggestion is also supported by the positive impact of customer role readiness on most co-creation experience dimensions. The central question is how to increase customer role readiness. Previous research focused on the importance of communication and guidance: the better the expectations regarding customers' role are communicated and the better customers are prepared to fulfill their role, the better customers' role readiness (Bowen, 1986; Graf, 2007). In other words, firms opting for co-creation need to invest in 
communication and guidance for their customers, so that customers feel ready to act as cocreators and do not experience failure.

Additionally, firms might also benefit from investing in co-creation environments with high technologization and connectivity, such as online customer communities (Füller, 2006) or VCEs (Nambisan and Baron, 2009, 2010). These co-creation environments provide not only online tools and devices that aid in achieving a co-creation task ( $c f$. technologization), but also allow customers to help one another ( $c f$. connectivity). As mentioned before, however, the importance of technologization and connectivity for co-creation experiences is not equally important for all customers, but depends on their expectations in terms of cocreation benefits.

In sum, customer heterogeneity in terms of expected co-creation benefits needs to be considered when designing co-creation environments. Since the expected co-creation benefits and the co-creation experience scale facilitate respectively the identification of different expected co-creation benefits and the evaluation of the co-creation experience, firms can use these scales as managerial tools to design and evaluate co-creation environments. To ensure that co-creation environments respond to customer heterogeneity in terms of expected cocreation benefits, it is not inconceivable that firms might benefit from having multiple environments to engage customers in co-creation (Verleye, 2014).

\section{Limitations and Future Research Directions}

It is important to note that the experimental subjects were undergraduate students. Therefore, data may be biased in favor of people who are familiar with computers and the Internet. On the one hand, there is some evidence that not all customers are able to deal with multimedia rich tools. Dellaert and Stremersch (2005) and Jeppesen (2005), for instance, argue that cocreating products and services with the help of multimedia rich tools might place an excessive strain on novice customers. On the other hand, people who are familiar with computers and 
Internet represent the majority of customers motivated to engage in co-creation (Franke and Piller, 2004).

Furthermore, the experimental subjects received instructions via instruction forms, but their impact on customer role readiness is unclear. Since we observed different role readiness levels among the subjects, future research should investigate what impact different types of instruction forms have on the role readiness of customers with different expectations in terms of co-creation benefits. It is, for instance, not inconceivable that people who like learning prefer to receive more general guidelines, while other people might prefer to get detailed instructions in co-creation situations.

In addition, this study focused on co-creation in interior design services. In this co-creation situation, technologization and connectivity might generate better cognitive experiences, because interior design allows for visualization. Visualization, however, is more difficult in some co-creation situations (e.g., co-creating the ideal wedding party). Moreover, certain cocreation situations require - contrary to co-creation in interior design services - a high level of emotional involvement (e.g., co-creating a personalized oncology therapy). In these situations, it is not inconceivable that a combination of technologization and connectivity might also affect the overall co-creation experience through other co-creation experience dimensions than the cognitive experience dimension. An online cancer community, for instance, might generate more opportunities to connect with like-minded people - and thus better social experiences - than other co-creation environments. Therefore, future research should investigate the impact of technologization and connectivity on the co-creation experience in different situations.

Next, future research should investigate whether the impact of connectivity on different cocreation experience dimensions would differ if there is non-technology-mediated versus technology-mediated connectivity, since this study only focused on non-technology-mediated 
connectivity (i.e., human-to-human connectivity). Additionally, the experimental study focused on co-creation in interactions with peers. This might differ from co-creation in interactions with professionals, since professionals are expected to be more focused on customers' needs and may have more - or complementary - expertise than peers. Conversely, customers might have different relationships with professionals than with peers, which can have an impact on their co-creation experience. As a final point in relation to connectivity, future research should investigate the impact of the number of co-creation partners on the cocreation experience dimensions, since experimental subjects completed the co-creation task in pairs.

Finally, future research should further validate our multidimensional co-creation experience scale in different co-creation situations. Additionally, further research might benefit from generating a better understanding of co-creation preferences of customers in various co-creation situations, since their expectations in terms of co-creation benefits might vary across co-creation situations. Finally, future research should also pay attention to the stability of customers' expected co-creation benefits over time.

\section{Conclusion}

This article contributes to the customer experience, the co-creation, and the new product and service development literature by providing insight into the customer experience in cocreation situations. Specifically, this study shows that the co-creation experience is a multidimensional phenomenon. Additionally, the findings suggest that co-creation experiences are affected by not only the co-creation process itself, but also characteristics of co-creation environments (i.e., technologization and connectivity) and (interactions among) co-creation actors (i.e., customer role readiness and interactional quality). The importance of these factors, however, differs according to customers' expectations in terms of co-creation benefits. Therefore, academics and practitioners should center their attention on taking 
customer heterogeneity in terms of expected co-creation benefits into account when designing co-creation environments and/or evaluating co-creation experiences.

\section{References}

Alam, I. (2002), "An exploratory investigation of user involvement in new service development", Journal of the Academy of Marketing Science, 30 (3) 250-261

Auh, S., Bell, S. J., McLeod, C. S. and Shih, E. (2007), "Co-production and customer loyalty in financial services", Journal of Retailing, 83 (3) 359-370

Beehr, T. A., Walsh, J. T. and Taber, T. D. (1976), "Relationship of stress to individually and organizationally valued states - higher-order needs as a moderator", Journal of Applied Psychology, 61 (1) 41-47

Berry, L. L., Bolton, R. N., Bridges, C. H., Meyer, J., Parasuraman, A. and Seiders, K. (2010), "Opportunities for innovation in the delivery of interactive retail services", Journal of Interactive Marketing, 24 (2) 155-167

Blau, P. M. (2004), Exchange \& power in social life, Wiley, New York.

Bogers, M., Afuah, A. and Bastian, B. (2010), "Users as innovators: A review, critique, and future research directions", Journal of Management, 36 (4) 857-875

Bolton, R. and Saxena-Iyer, S. (2009), "Interactive services: A framework, synthesis and research directions", Journal of Interactive Marketing, 23 (1) 91-104

Bowen, D. E. (1986), "Managing customers as human resources in service organizations", Human Resources Management, 25 (3) 371-383

Carbonell, P., Rodriguez-Escudero, A. I. and Pujari, D. (2009), "Customer involvement in new service development: An examination of antecedents and outcomes", Journal of Product Innovation Management, 26 (5) 536-550 
Chan, K. W., Yim, C. K. and Lam, S. S. K. (2010), "Is customer participation in value creation a double-edged sword? Evidence from professional financial services across cultures", Journal of Marketing, 74 (3) 48-64

Dellaert, B. G. C. and Stremersch, S. (2005), "Marketing mass-customized products: Striking a balance between utility and complexity", Journal of Marketing Research, 42 (2) 219-227 Downie, M., Mageau, G. A. and Koestner, R. (2008), "What makes for a pleasant social interaction? Motivational dynamics of interpersonal relations", Journal of Social Psychology, 148 (5) 523-534

Etgar, M. (2008), "A descriptive model of the consumer co-production process", Journal of the Academy of Marketing Science, 36 (1) 97-108

Fang, E., Palmatier, R. W. and Evans, K. R. (2008), "Influence of customer participation on creating and sharing of new product value", Journal of the Academy of Marketing Science, 36 (3) $322-336$

Fornell, C. and Larcker, D. F. (1981), "Evaluating structural equation models with unobservable variables and measurement error", Journal of Marketing Research, 18 (1) 3950

Franke, N., Keinz, P. and Schreier, M. (2008), "Complementing mass customization toolkits with user communities: How peer input improves customer self-design", Journal of Product Innovation Management, 25 (6) 546-559

Franke, N. and Piller, F. (2004), "Value creation by toolkits for user innovation and design: The case of the watch market", Journal of Product Innovation Management, 21 (6) 401-415 Franke, N. and Schreier, M. (2010), "Why customers value self-designed products: The importance of process effort and enjoyment", Journal of Product Innovation Management, 27 (7) $1020-1031$ 
Franke, N. and Shah, S. (2003), "How communities support innovative activities: An exploration of assistance and sharing among end-users", Research Policy, 32 (1) 157-178 Franke, N. and von Hippel, E. (2003), "Satisfying heterogeneous user needs via innovation toolkits: The case of apache security software", Research Policy, 32 (7) 1199-1215 Füller, J. (2006), "Why consumers engage in virtual new product developments initiated by producers", Advances in Consumer Research, 33) 639-646

Füller, J. (2010), "Refining virtual co-creation from a consumer perspective", California Management Review, 52 (2) 98-122

Gelman, A. and Hill, J. (2007), Data analysis using regression and multilevel/hierarchical models, Cambridge University Press, New York, NY.

Gelman, A. and Rubin, D. B. (1992), "Inference from iterative simulation using multiple sequences", Statistical Science, 7 (4) 457-472

Gentile, C., Spiller, N. and Noci, G. (2007), "How to sustain the customer experience: An overview of experience components that co-create value with the customer", European Management Journal, 25 (5) 395-410

Graf, A. (2007), "Changing roles of customers: Consequences for hrm", International Journal of Service Industry Management, 18 (5) 491-509

Holbrook, M. B. and Hirschman, E. C. (1982), "The experiential aspects of consumption consumer fantasies, feelings, and fun", Journal of Consumer Research, 9 (2) 132-140 Hox, J. J. (2010), Multilevel analysis, Routledge, New York.

Hoyer, W. D., Chandy, R., Dorotic, M., Krafft, M. and Singh, S. S. (2010), "Consumer cocreation in new product development", Journal of Service Research, 13 (3) 283-296 Jeppesen, L. B. (2005), "User toolkits for innovation: Consumers support each other", Journal of Product Innovation Management, 22 (4) 347-362 
Kahn, R. L., Wolfe, D. M., Quinn, R. P., Snoek, J. D., Rosenthal, R. A., John, W. and Sons, I. (1964), Organizational stress: Studies in role conflict and ambiguity, John Wiley and Sons, New York.

Ketchen, D. J. and Shook, C. L. (1996), "The application of cluster analysis in strategic management research: An analysis and critique", Strategic Management Journal, 17 (6) 441458

Klaus, P. and Maklan, S. (2012), "Exq: A multiple-item scale for assessing service experience", Journal of Service Management, 23 (1) 5-33

Meuter, M. L., Bitner, M. J., Ostrom, A. L. and Brown, S. W. (2005), "Choosing among alternative service delivery modes: An investigation of customer trial of self-service technologies", Journal of Marketing, 69 (2) 61-83

Mustak, M., Jaakkola, E. and Halinen, A. (2013), "Customer participation and value creation: A systematic review and research implications", Managing Service Quality, 23 (4) 341-359 Nambisan, S. (2002), "Designing virtual customer environments for new product development: Toward a theory", Academy of Management Review, 27 (3) 392-413 Nambisan, S. and Baron, R. A. (2009), "Virtual customer environments: Testing a model of voluntary participation in value co-creation activities", Journal of Product Innovation Management, 26 (4) 388-406

Nambisan, S. and Baron, R. A. (2010), "Different roles, different strokes: Organizing virtual customer environments to promote two types of customer contributions", Organization Science, 21 (2) 554-572

O'Hern, M. and Rindfleisch, A. (2008), "Customer co-creation: A typology and research agenda", working paper, School of Business, University of Wisconsin, Wisconsin, 1 December. 
Palmer, A. (2010), "Customer experience management: A critical review of an emerging idea", Journal of Services Marketing, 24 (2-3) 196-208

Payne, A. F., Storbacka, K. and Frow, P. (2008), "Managing the co-creation of value", Journal of the Academy of Marketing Science, 36 (1) 83-96

Pine, J. B. and Gilmore, J. H. (1999), The experience economy: Work is theatre and every business a stage, Harvard Business School Press, Boston, Massachusetts.

Prahalad, C. K. and Ramaswamy, V. (2003), "The new frontier of experience innovation", Mit Sloan Management Review, 44 (4) 12-18

Rizzo, J. R., House, R. J. and Lirtzman, S. I. (1970), "Role conflict and ambiguity in complex organizations", Administrative Science Quarterly, 15 (2) 150-162

Ryan, R. M. and Connell, J. P. (1989), "Perceived locus of causality and internalization examining reasons for acting in 2 domains", Journal of Personality and Social Psychology, 57 (5) 749-761

Ryan, R. M. and Deci, E. L. (2000), "Self-determination theory and the facilitation of intrinsic motivation, social development, and well-being", American Psychologist, 55 (1) 68-78 Schirr, G. R. (2012), "Flawed tools: The efficacy of group research methods to generate customer ideas", Journal of Product Innovation Management, 29 (3) 473-488

Sweeney, J. C. and Soutar, G. N. (2001), "Consumer perceived value: The development of a multiple item scale", Journal of Retailing, 77 (2) 203-220

Thomke, S. and von Hippel, E. (2002), "Customers as innovators: A new way to create value", Harvard Business Review, 80 (4) 74-81

Vargo, S. L. and Lusch, R. F. (2008), "Service-dominant logic: Continuing the evolution", Journal of the Academy of Marketing Science, 36 (1) 1-10 
Verhoef, P. C., Lemon, K. N., Parasuraman, A., Roggeveen, A., Tsiros, M. and Schlesinger, L. A. (2009), "Customer experience creation: Determinants, dynamics and management strategies", Journal of Retailing, 85 (1) 31-41

Verleye, K. (2014), "Designing service interfaces for customer engagement in the creation of value", in J. Kandampully, Ed., Customer experience management: Enhancing experience and value through service management. Kendal Hunt Publishing Company, Dubuque, USA, pp. 73-97.

von Hippel, E. (2001), "Innovation by user communities: Learning from open-source software", Mit Sloan Management Review, 42 (4) 82-86 Yuan, Y. and MacKinnon, D. P. (2009), "Bayesian mediation analysis", Psychological Methods, 14 (4) 301-322

Zeithaml, V. A., Parasuraman, A. and Berry, L. L. (1990), Delivery quality service. Balancing customer perceptions and expectations, The Free Press, New York. 


\section{Appendix: Screenshots of Interior Design Software}

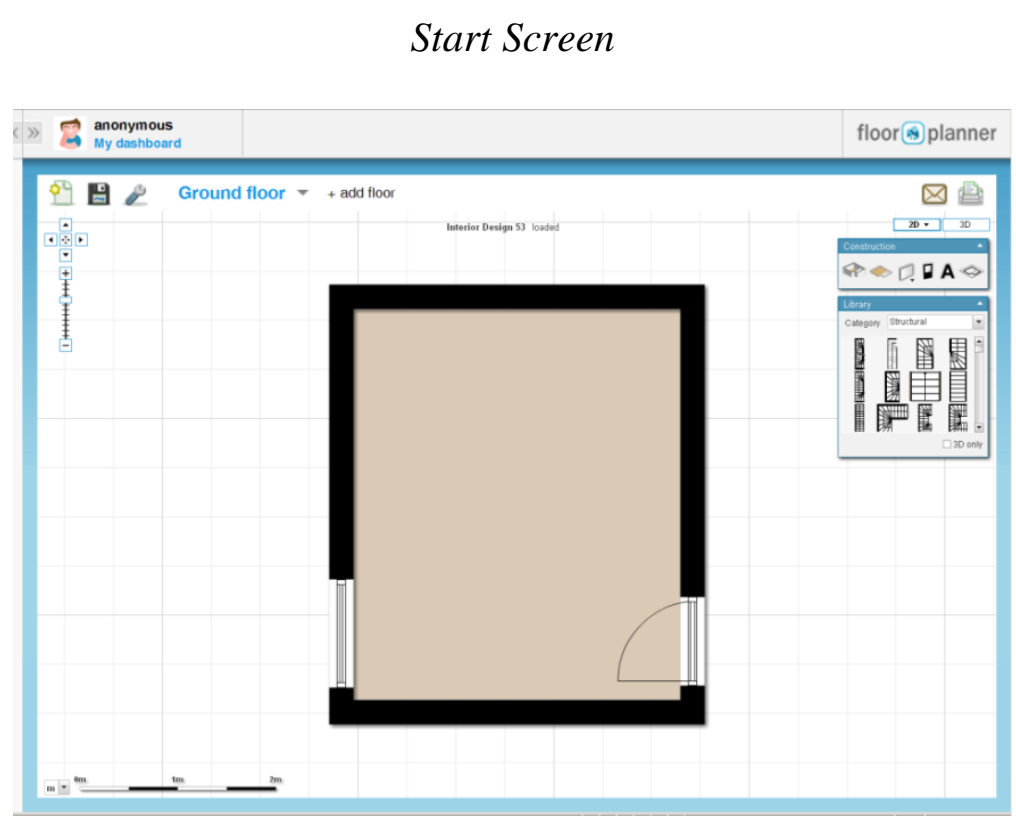

Output in $2 D$ and $3 D$
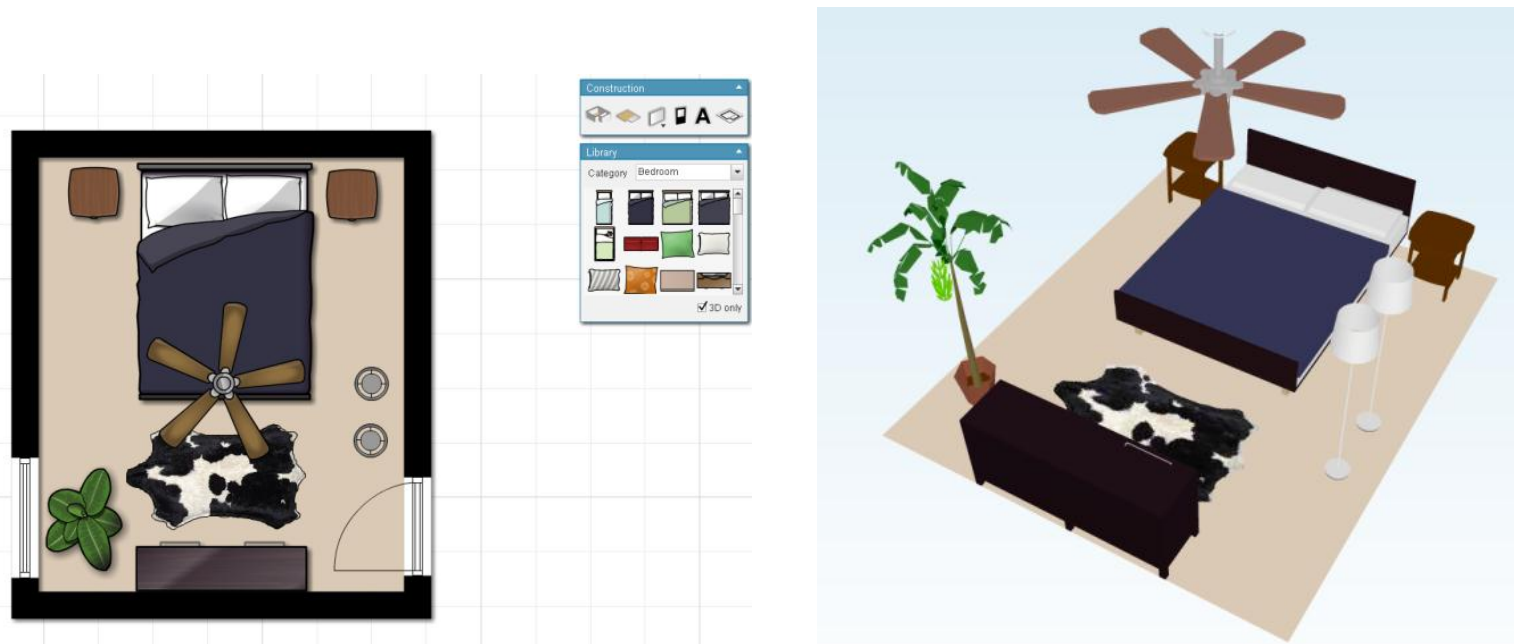

Note. The software is available at www.floorplanner.com. We made an agreement with the company, so that subjects did not have to sign up and got immediate access to the tool. The subjects' start screen differed from the original start screen at www.floorplanner.com. The original start screen is blank, so that subjects can design both the floor plan and the interiors of the rooms on the floor plan. To keep the focus on interior design, the experimental start screen showed a floor plan of an average bedroom, which could be adapted if desired. 
FIGURE 1. Theoretical Framework

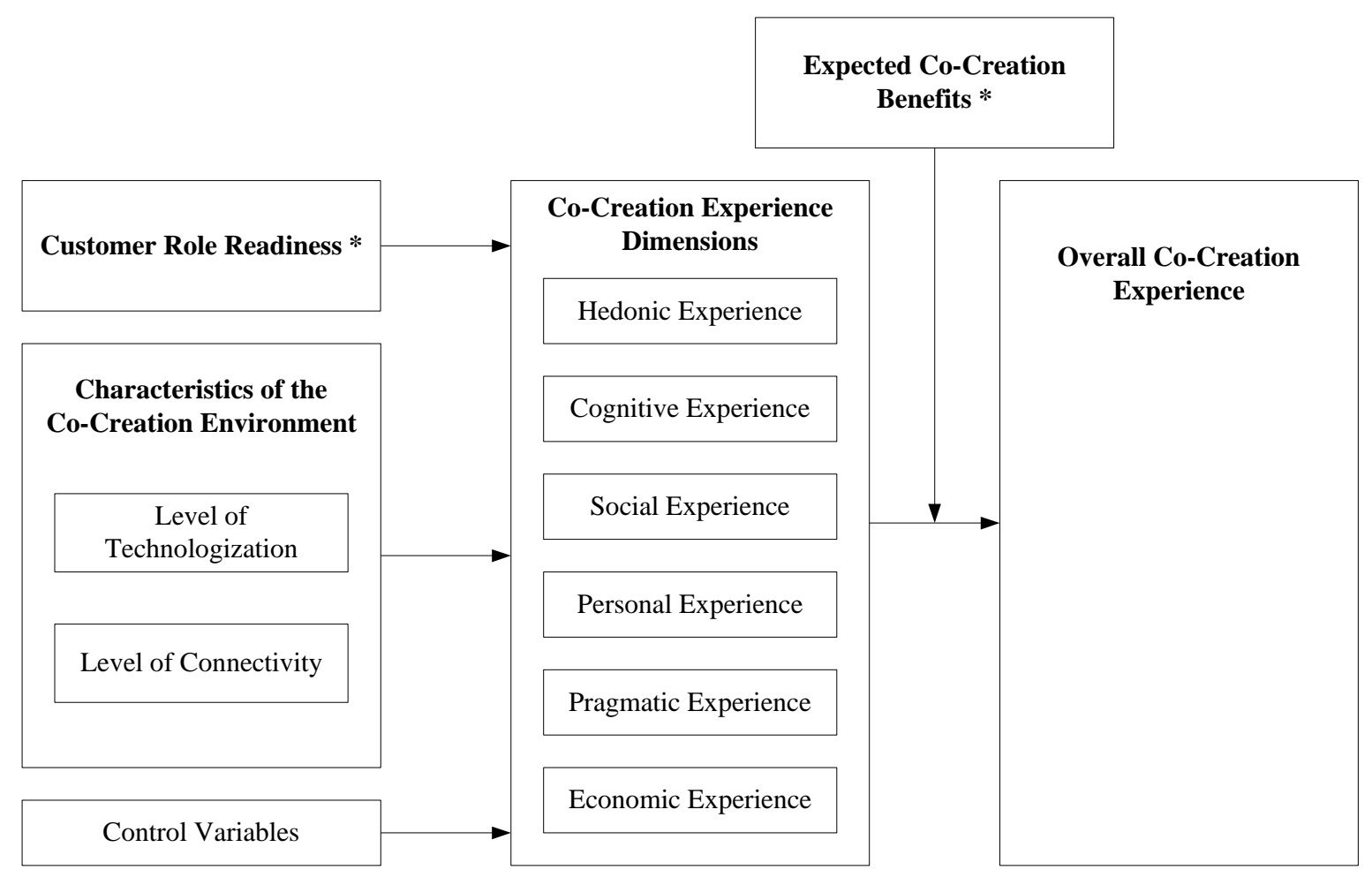

Note. $*$ characteristics of co-creating customers. 
FIGURE 2. Cluster Means for Expected Co-Creation Benefits

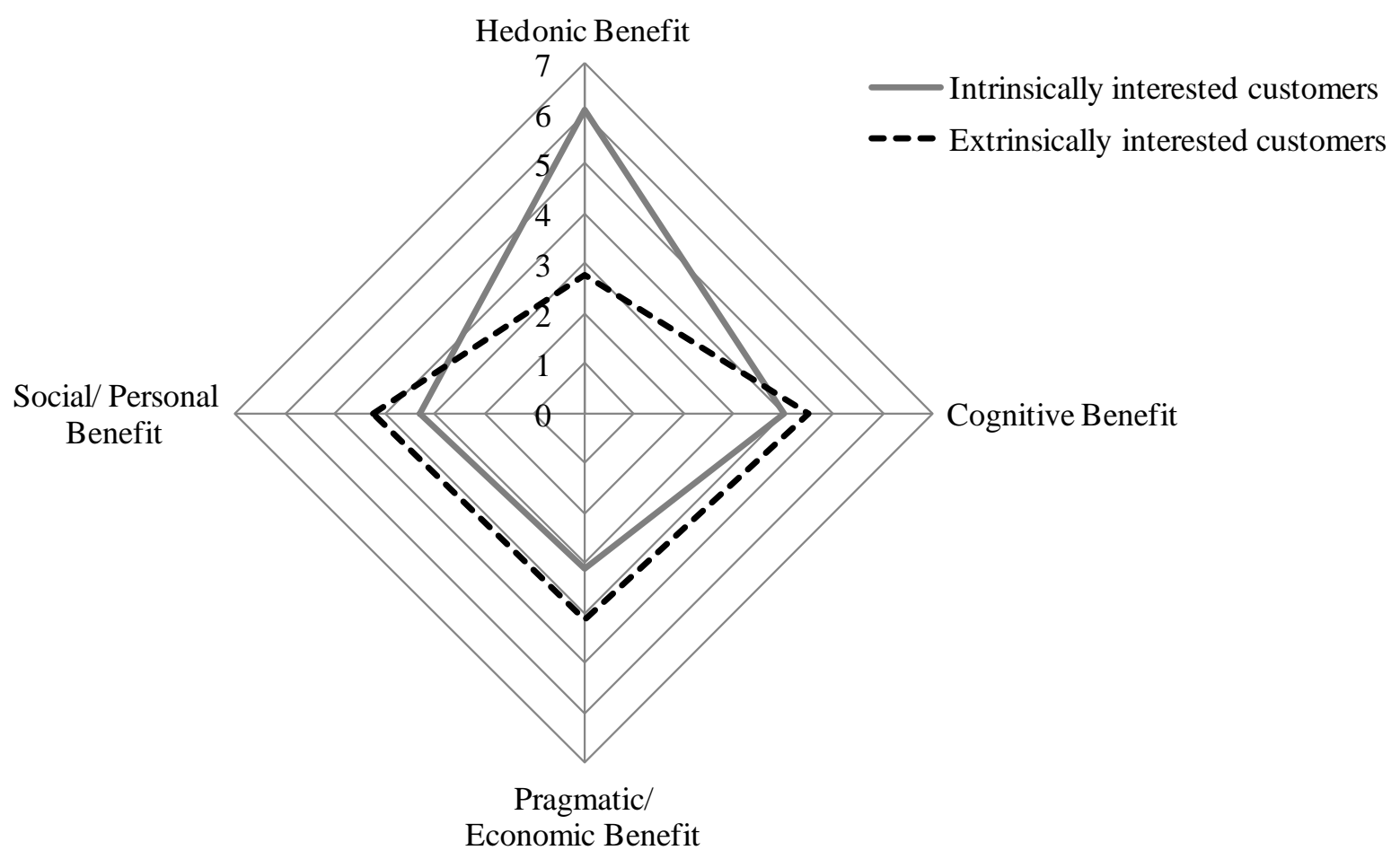


FIGURE 3. Interaction between Technologization and Connectivity on Cognitive Experience

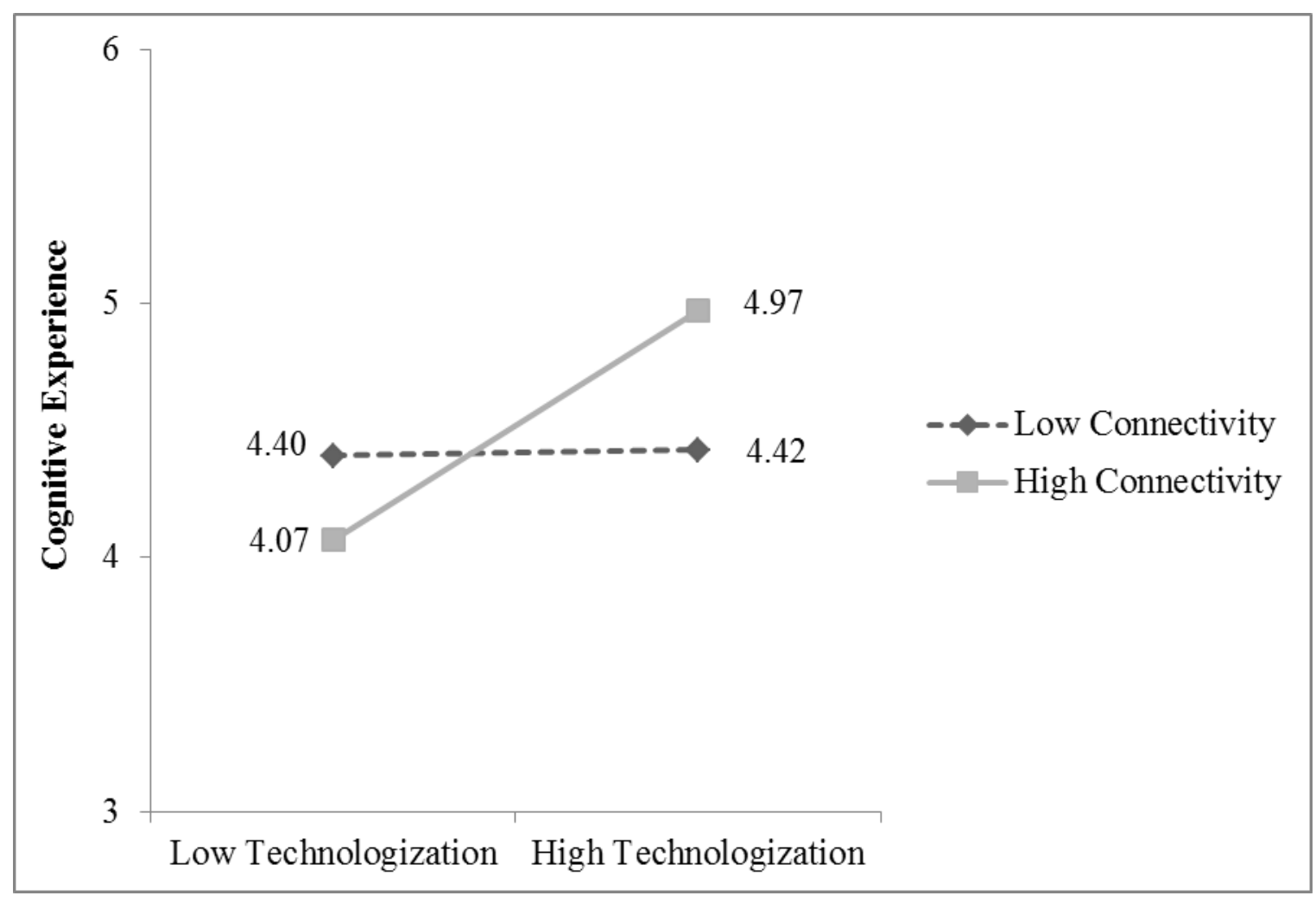


TABLE 1. Multidimensional Co-Creation Experience Scale Items

\begin{tabular}{|c|c|c|}
\hline Scale & Items & Scales from which items are adapted \\
\hline $\begin{array}{l}\text { Hedonic } \\
\text { experience }\end{array}$ & $\begin{array}{l}\text { It was a nice experience } \\
\text { It was fun } \\
\text { I enjoyed it }\end{array}$ & $\begin{array}{l}\text { Adapted from self-regulation } \\
\text { questionnaire - intrinsic motivation } \\
\text { scale (Ryan and Connell, 1989) }\end{array}$ \\
\hline \multirow[t]{4}{*}{$\begin{array}{l}\text { Cognitive } \\
\text { experience }\end{array}$} & $\begin{array}{l}\text { It allowed me to keep up with new } \\
\text { ideas and innovations } \\
\text { It enabled me to come up with new } \\
\text { ideas }\end{array}$ & $\begin{array}{l}\text { Adapted from intrinsic innovation } \\
\text { interest scale (Füller, 2010) }\end{array}$ \\
\hline & $\begin{array}{l}\text { I could test my capabilities } \\
\text { I improved my skills }\end{array}$ & $\begin{array}{l}\text { Adapted from gain knowledge scale } \\
\text { (Füller, 2010) }\end{array}$ \\
\hline & I gained a sense of accomplishment & $\begin{array}{l}\text { Adapted from achievement-challenge- } \\
\text { self efficacy scale (Füller, 2006) }\end{array}$ \\
\hline & I gained new knowledge/expertise & $\begin{array}{l}\text { Adapted from knowledge acquisition } \\
\text { scale (Füller, 2006) }\end{array}$ \\
\hline \multirow[t]{2}{*}{$\begin{array}{l}\text { Social } \\
\text { experience }\end{array}$} & $\begin{array}{l}\text { I met others with whom I share } \\
\text { similar interests } \\
\text { I am able to connect with other } \\
\text { people }\end{array}$ & $\begin{array}{l}\text { Adapted from make friends scale } \\
\text { (Füller, 2006) }\end{array}$ \\
\hline & The interaction was pleasant & $\begin{array}{l}\text { Adapted from customer relational value } \\
\text { scale (Chan et al., 2010) }\end{array}$ \\
\hline \multirow[t]{3}{*}{$\begin{array}{l}\text { Personal } \\
\text { experience }\end{array}$} & $\begin{array}{l}\text { It raised ideas that I can introduce to } \\
\text { others }\end{array}$ & $\begin{array}{l}\text { Adapted from show idea scale (Füller, } \\
\text { 2010) }\end{array}$ \\
\hline & $\begin{array}{l}\text { I could make others aware of my } \\
\text { knowledge and ideas }\end{array}$ & $\begin{array}{l}\text { Adapted from recognition-visibility } \\
\text { scale (Füller, 2006) }\end{array}$ \\
\hline & $\begin{array}{l}\text { I made a good impression on other } \\
\text { people }\end{array}$ & $\begin{array}{l}\text { Adapted from consumer perceived } \\
\text { social value scale (Sweeney and Soutar, } \\
2001 \text { ) }\end{array}$ \\
\hline $\begin{array}{l}\text { Pragmatic } \\
\text { experience }\end{array}$ & $\begin{array}{l}\text { I had control over the quality } \\
\text { The quality was in my hands } \\
\text { I had an impact on the degree to } \\
\text { which my preferences were met } \\
\text { The risk of failure was limited }\end{array}$ & $\begin{array}{l}\text { Adapted from customer economic } \\
\text { value scale (Chan et al., 2010) }\end{array}$ \\
\hline $\begin{array}{l}\text { Economic } \\
\text { experience }\end{array}$ & $\begin{array}{l}\text { I got a compensation in line with the } \\
\text { effort made } \\
\text { I got an appropriate reward in return } \\
\text { for my input } \\
\text { I got a fair return }\end{array}$ & $\begin{array}{l}\text { Adapted from compensation-monetary } \\
\text { reward scale (Füller, 2010) }\end{array}$ \\
\hline
\end{tabular}


TABLE 2. CFA Results for Co-Creation Experience Scale

Constructs and Items

Factor Loading

Hedonic experience $(C R=.96 ; A V E=.88)$

It was a nice experience

0.88

It was fun

0.96

I enjoyed it

Cognitive experience $(C R=.90 ; A V E=.66)$

I can improve my skills

I gain new knowledge/ expertise

0.73

I can test my capabilities

0.87

$\begin{array}{ll}\text { It allows me to keep up with new ideas and innovations } & 0.90\end{array}$

$\begin{array}{ll}\text { It enables me to come up with new ideas } & 0.78\end{array}$

Social/personal experience $(C R=.90 ; A V E=.63)$

The interaction is pleasant

I am able to connect with other people $\quad 0.55$

$\begin{array}{ll}\text { I can make others aware of my knowledge and ideas } & 0.79\end{array}$

$\begin{array}{ll}\text { I can make a good impression on other people } & 0.87\end{array}$

$\begin{array}{ll}\text { I meet others with whom I share similar interests } & 0.84\end{array}$

Pragmatic/economic experience $(C R=.87 ; A V E=.53)$

I got a compensation according to the effort made $\quad 0.63$

$\begin{array}{ll}\text { I got a fair return } & 0.69\end{array}$

$\begin{array}{ll}\text { I got an appropriate reward in return for my input } & 0.64\end{array}$

$\begin{array}{ll}\text { I had control over the quality } & 0.77\end{array}$

$\begin{array}{ll}\text { The quality was in my hands } & 0.81\end{array}$

$\begin{array}{ll}\text { I had an impact on the degree to which my preferences were met } & 0.79\end{array}$

Overall experience $(C R=.93 ; A V E=.77)$

$\begin{array}{ll}\text { dissatisfactory - satisfactory } & 0.93 \\ \text { negative - positive } & 0.93 \\ \text { poor - excellent } & 0.89 \\ \text { disappointing - delightful } & 0.76\end{array}$

Note. $C R=$ composite reliability; $\mathrm{AVE}=$ average variance extracted; $\chi^{2}=515.78, d f=220$, the comparative fit index $(\mathrm{CFI})=0.96$, Tucker-Lewis index $(\mathrm{TLI})=0.96$, root mean square error of approximation $($ RMSEA $)=0.09$, and standardized root mean squared residual $(\mathrm{sRMR})=0.07$. 
TABLE 3. Means, Standard Deviations, Cronbach's Alpha, and Correlation Matrix

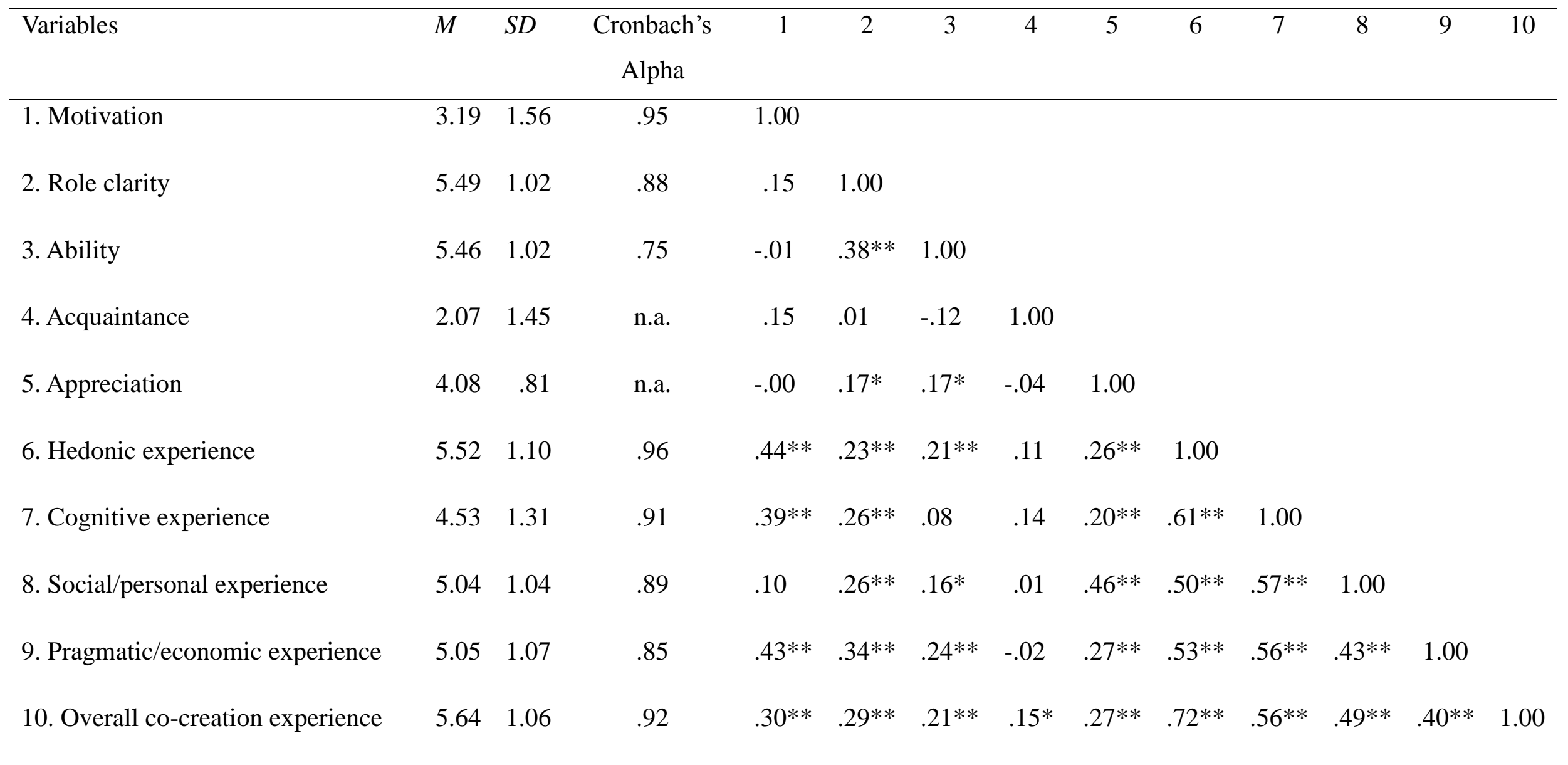

Note. Acquaintance = acquaintanceship with co-creation partner; Appreciation = co-creation partner's appreciation for the customer's input; $M=$ mean construct score (unweighted); $S D=$ standard deviation; $* p<.05 ; * * p<.01$. 
TABLE 4. Antecedents of Co-Creation Experience Dimensions and Overall Co-Creation Experience

\begin{tabular}{|c|c|c|c|c|c|}
\hline \multirow[t]{2}{*}{ Variables } & $\mathrm{HE}$ & $\mathrm{CE}$ & SPE & PEE & OCE \\
\hline & $\alpha$ & $\alpha$ & $\alpha$ & $\alpha$ & $\beta$ \\
\hline Intercept & $2.00 * *$ & 1.13 & $1.40 * *$ & $1.25^{*}$ & $1.84 * *$ \\
\hline Motivation & $.27 * *$ & $.29 * *$ & .07 & $.28 * *$ & \\
\hline Role clarity & .06 & $.22 *$ & $.17 *$ & $.22 * *$ & \\
\hline Ability & $.16^{*}$ & .00 & .03 & .10 & \\
\hline TECH & .31 & .04 & .02 & .29 & \\
\hline CONN & -.27 & -.34 & .28 & -.04 & \\
\hline $\mathrm{TECH}^{*} \mathrm{CONN}$ & .46 & $.87 * *$ & .26 & .24 & \\
\hline Acquaintance & .07 & .08 & .00 & -.05 & \\
\hline Appreciation & $.28 * *$ & $.25^{*}$ & $.52 * *$ & $.27 * *$ & \\
\hline $\mathrm{HE}$ & & & & & $.55^{* *}$ \\
\hline $\mathrm{CE}$ & & & & & $.13^{*}$ \\
\hline SPE & & & & & $.15^{*}$ \\
\hline PEE & & & & & -.05 \\
\hline
\end{tabular}

Note. $\mathrm{HE}=$ hedonic experience, $\mathrm{CE}=$ cognitive experience, $\mathrm{SPE}=$ social/personal experience, $\mathrm{PEE}=$ pragmatic/economic experience, $\mathrm{OCE}=$ overall co-creation experience, $\mathrm{TECH}=$ technologization (low $=$ reference category) CONN $=$ connectivity (low $=$ reference category); Acquaintance $=$ acquaintanceship with co-creation partner; Appreciation = co-creation partner's appreciation for the customer's input; * $p<.05 ; * * p<.01$. 
TABLE 5. Antecedents of Overall Co-Creation Experience per Customer Segment

\begin{tabular}{llc}
\hline & Variables & $\beta$ \\
\hline Subsample 1: & Intercept & $1.61^{* *}$ \\
intrinsically interested & Hedonic experience & $.58^{* *}$ \\
customers $(n=112)$ & Cognitive experience & $.24^{* *}$ \\
& Social/personal experience & .04 \\
& Pragmatic/economic experience & -.09 \\
\hline Subsample 2: & Intercept & $1.02^{*}$ \\
extrinsically interested & Hedonic experience & $.64^{* *}$ \\
customers $(n=68)$ & Cognitive experience & -.07 \\
& Social/personal experience & $.27^{* *}$ \\
& Pragmatic/economic experience & .02
\end{tabular}

Note. ${ }^{*} p<.05 ; * * p<.01$. 
${ }^{[1]}$ This reasoning builds on the customer experience literature, which considers customer experience as a multidimensional phenomenon differing from service quality (e.g., Verhoef et al., 2009; Klaus and Maklan, 2012).

${ }^{[2]}$ The co-creation experience scale includes both the items related to the six co-creation experience dimensions (22 items) and the items related to the overall co-creation experience (4 items).

${ }^{[3]}$ We used noninformative prior distributions, because we fit hierarchical models with more than five groups without knowledge about the parameters beyond the data included in the analysis (see also Gelman, A. (2006), "Prior distributions for variance parameters in hierarchical models (comment on an articular by Browne and Draper)”, Bayesian Analysis, Vol. 1 No. 3, pp. 515-533). In line with the recommendations of Gelman (2006), we also checked the posterior distributions, which showed that the noninformative prior distributions made sense. 